\title{
Hashtagging as a communication strategy
}

\section{Orlova}

Taras Shevchenko National University of Kyiv, Kyiv, Ukraine

Corresponding author. E-mail: velena_1@ukr.net

Paper received 03.02.19; Accepted for publication 08.02.19.

\section{https://doi.org/10.31174/SEND-Ph2019-191VII57-07}

\begin{abstract}
The article considers the notion of hastagging in the paradigm of computer-mediated communication. The author refers to general classification of communication strategies to specify communicative role of hashtagging on social networking websites, i.e. Facebook, Instagram, and Twitter. It is defined that users employ I-strategy for self-portraying and attracting attention to their personal profiles, You-strategy for establishing contact with the audience, and We-strategy for creating sense of community.
\end{abstract}

Keywords: communication strategy, hashtag, Internet, social networking.

Rapid development of technologies stimulates further enhancement of social media communication. In 2004, a new social networking service Facebook was launched. It has become one of the most popular social networks with more than 2.27 billion active users in 2018 [2].

The launch of microblogging service Twitter in 2006 became another milestone in development of social networking. Twitter allowed its users to interact with messages, known as "tweets" that were originally restricted to 140 characters. In 2017 the number of permitted characters in one message was doubled. By the end of 2018 this social networking service counted 336 million active users worldwide [13].

Both social networking services allowed their users to share text messages along with visual content (by attaching pictures, photo and video files). Originally, the structural organisation of Facebook posts and Twitter tweets presupposed that visual content had a complementary nature, i.e. users shared news containing text or texts and visual materials, but nowadays it is allowed to post messages containing merely visual component.

Next step in the expansion of social networking was the introduction of photo and video-sharing networking service Instagram in 2010 that by the end of 2018 had 1 billion active users [7]. The main distinguishing feature of this service is the obligatory character of visual component. Users are allowed to upload pictures or video files while text remains optional.

Though social networking services Facebook, Twitter, and Instagram differ in their organisational structure and message design, some specific features can be listed as common. The primary function of communicating via these services is to share content with other users and get feedback from them. Communication via Facebook, Twitter, and Instagram presupposes both verbal and nonverbal reaction from communicants. Verbal feedback is formed with comments typed under the message shared by the sender. Non-verbal feedback in social networking is associated with the reaction in form of sharing (retweeting) or liking the posted message. The success of communication process in this environment is assessed according to the number of reactions to the message. From this perspective users strive to get more followers and attract their attention to the posted items.

The aim of this article is to consider hastagging as a specific feature of computer-mediated communication, i.e. interaction on such social networking websites as Facebook, Intagram, and Twitter. Adding hashtags to messages is seen as a communicative move that has specific intention, consequently hashtagging is regarded within communication strategy paradigm.

The research includes such methods as deduction, generalisation, quantitative analysis, content analysis.

To increase the visibility of the posted content social networking users add specific keywords (hashtags) to the verbal part of their messages. A hashtag is a type of metadata tag used on social networks, allowing users to apply dynamic, user-generated tagging which makes it possible for others to easily find messages on a specific topic or with a particular content. A hashtag is composed of two obligatory parts: a pond sign (\#) and verbal message (a key word or a phrase). At first, the pond sign was introduced in Internet relay chat networks in 1988 to label groups and topics [6]. In 2007 one of the Twitter users suggested using the pond sign to tag topics on the microblog [9]. The use of the hashtag was aimed at fostering the navigation through the microblog in search of relevant content. In other words, hashtag on Twitter is seen as a way of categorizing messages according to their relevance from the users' perspective. In 2009, Twitter began to hyperlink all hashtags in tweets to Twitter search results for the hashtagged word and in a year the microblogging service introduced "Trending Topics" section that displays hashtags that are rapidly becoming popular. Therefore, Twitter users become aware that the most popular topics in the USA on 28.01.2019 were \#MondayMotivation (with 134 thousand tweets), \#MondayMorning (25 thousand tweets), \#MakeMomHappyIn3Words (4 thousand tweets). These Trending Topics continuously change and vary for different regions, as a result such structural organization complies with the up-to-dateness principle of computer-mediated communication.

The growing popularity of hashtags has led to the extension of these key words beyond the Internet domain. Advertisers started displaying hashtags on screen to create brand awareness, increase the visibility of content, gain new audience, boost shares and likes, and to get audience involved. As a result, users of social networking services started posting messages containing slogan-like hashtags that are associated with recognizable brands, e.g. \#DeclareYourStyle (Forever 21), \#DoUsAFlavour (Lay's), \#ShareACoke (Coca-Cola), \#WorthSaying (L'Oréal Paris). On the one hand, these hashtags launch social campaigns as in \#WorthSaying (women are encouraged to talk about something that matters to them), and show that companies care about customers' feelings and are eager to 
get feedback (as in \#DoUsAFlavour, Lay's askes customers to vote for their favourite flavour), but on the other hand, it is one more way to advertise brand (\#WorthSaying correlates with the brand's tagline "Because you are worth it"). The major anticipated effect of using hashtags in advertising is starting discussion via social media.

The fact that hashtags have become an inseparable part of Internet communication is recorded by Oxford English Dictionary as this neologism was included in the dictionary in 2014. A hashtag is defined as "A word or phrase preceded by a hash sign (\#), used on social media websites and applications, especially Twitter, to identify messages on a specific topic" [8].

From the linguistic point of view, a hashtag is defined as a word or a phrase used with the purpose of classifying or categorizing messages on social networking websites [8]. Another approach considers hashtags as specific syntactic units on social networks [4]. The nature of online communication presupposes the necessity to shorten texts due to formal (symbol limit on Twitter) and informal (specific character of short text perception) factors. Adding precise key words to the message, addressers help their potential addressees navigate through the endless flow of information on the websites.

We adhere to the idea that hashtags refer to specific features of social networking syntax due to the emerged possibility to hyperlink key words. For example, Instagram account launches weekend hashtag projects (shortened to WHP) and one of the most recent in January 2019 was \#WHPinspiredby. In the course of this challenge Instagram users are suggested to modernize classic paintings, stage a photo, and upload it with the hashtag \#WHPinspiredby to submit visuals to the project. All Instagram users can click on this hashtag or type the key word in a search field to get access to all posts containing this hashtag in the text part of a post. Search result on Instagram shows 8558 entries containing \#WHPinspiredby hashtag. As an example, we can consider one of the messages with this hashtag posted by an Instagram user colorcompanion: (Pic. 1)“@witenry Good Morning! 7) Use \#colorcompanion for features \#candyminimal \#thecolorshift \#bhgcolor \#colormehappy \#popyacolour \#huntgramcolor \#simplethingsmadebeautiful \#modernart \#contemporaryart \#dsrainbow \#dscollections \#crafttherainbow \#psimadethis \#acolorstory \#abmcrafty \#colorventures \#ihavethisthingwithcolor \#whpinspiredby \#pocket_colors \#ilovecolor \#colormehappy \#pantone \#candyminimal \#raw_colours \#dscolor \#happycolors [16].

This message consists of two parts: an obligatory visual content (a photogtaph), and an optional verbal message. The latter can be further subdivided into two parts: coherent message and a list of hashtags added as an afterthought. This example illustrates an overuse of hashtags, a lot of which contain lexemes "color" and "art". An excessive hashtagging (the author of the message included 27 hashtags in the post) is associated with the author's intention to reach vast audience and attract attention of as many followers as possible.

One more entry containing \#WHPinspiredby hashtag was posted by helenbreznik: (Pic. 2) "\#whpinspiredby \#fridakahlo \#paints \#fridakahloinspired \#madewithdefekt \#modern \#interpretation \#flowing \#pixles" [16]. Structur- ally, this message is similar to the previous one, but unlike the former, the visual part is a short video and the verbal part contains mere list of hashtags. In this case, the message the author tries to deliver is encoded in key words. In other words, the author encoded the message expressing the author's desire to take part in weekend hashtag project and for this purpose a video inspired by Frida Kahlo's paintings, where pixel effect was applied, was created. Consequently, the author uses hashtags as a means of complying with the least effort principle.

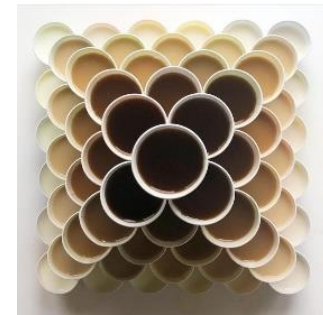

Pic. 1

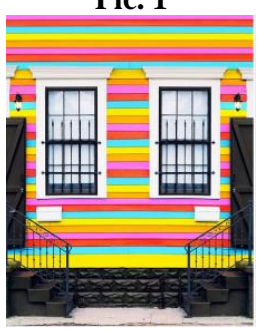

Pic. 3

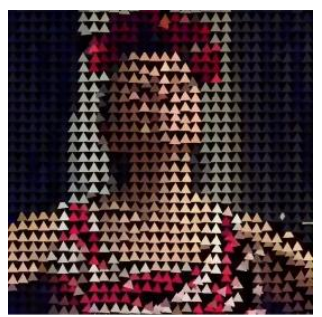

Pic. 2

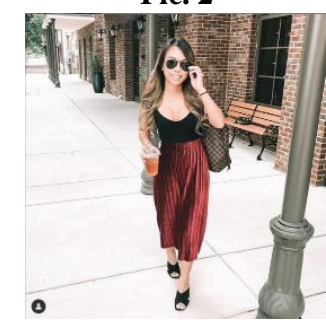

Pic. 4
Is it important to note that hashtags may go beyond the social networking service they originated from. The above mentioned hashtag was introduced by Instagram, but messages containing it may be easily traced on Facebook and Twitter. For example, a Facebook user Matt Crump posted on his timeline: "I fell in love with color the moment my high school art teacher played the \#YellowSubmarine. I was transfixed by its bursting psychedelic hues for 90 spellbinding minutes, and my brain has been filled with rainbows ever since จ \#WHPinspiredby @ thebeatles (Pic. 3)" [15]. The fact that one and the same key word is used on various social networking websites proves the ability of hashtags to arrange endless hypertexts.

Considering specific features of social media and general principles of computer-mediated communication we can arrive at the conclusion that the main reason for social networking is sharing content for further feedback from the audience. Taking into account this communicative aim we can study communication strategies used by communicants in social networking environment to reach set goals.

In linguistics, communication strategy is associated with problem-solving in the course of interaction. It is used by an individual to overcome the crisis which occurs when language structures are inadequate to convey the individual's thought [12, p. 195]. Communication strategies are defined as potentially conscious plans for solving what to an individual presents itself as a problem in reaching a particular communicative goal $[3$, p. 36]. These are strategies which a language user employs in order to achieve his intended meaning on becoming aware of problems arising during the planning phase of an utterance due to his own linguistic shortcomings [10, p. 72]. 
According to the given definitions, communication strategies arise as mental plans aimed at achieving intended goals, but the scholars do not consider interlocutor's engagement in problem-solving activity. In contrast to the above mentioned view, Tarone states that communication strategy is a mutual attempt of two interlocutors to agree on a meaning in situations where requisite meaning structures do not seem to be shared [12, p. 65].

In East European tradition, communication strategy is defined as a speech behaviour arrangement in accordance with the general communicant's plan and intention $[1, \mathrm{p}$. 89]; as a general plan of speech behaviour (a set of planned speech acts) aimed at achieving final communicative goal $[11$, p. 6]. According to Issers, communication strategy is an overarching goal [5, p. 52] - it is a set of speech acts intended at achieving communication goal.

Due to specific features of analysed communicative environment, general communicative goal, and absence of exhaustive classification, we adhere to the classification suggested by the Russian linguist Baoyan U [14]. We distinguish I-strategy (self-portraying and creating virtual identity), You-strategy (initiating interaction) and Westrategy (integrating, building sense of community).

Self-portraying on social networking websites is achieved trough sharing both verbal and visual content. Users may upload profile pictures, post messages with their photographs, write messages revealing their feelings, preferences, or attitudes.

You-strategy reveals communicants' readiness for interaction. As it has already been mentioned, the main purpose of communication on social networking services is getting feedback from the audience. Users employ different verbal tactics to trigger a conversation (such as greeting with real or potential addressees, asking questions, saying farewells, expressing wishes, making compliments and so on).

We-strategy is associated with building up a sense of community. On the one hand, users of a particular social network are considered to be a separate social group. On the other hand, there exists additional subdivision of these social groups into smaller ones according to their interests. By following different accounts users refer themselves to smaller social units within one big group.

Various brands resort to community-building strategy with the help of hashtags. For example, an American fast fashion retailer Forever 21 launched a contest on Instagram in 2013. Though the competition came to an end, brand's devotees are still posting messages with the hashtag \#DeclareYourStyle that now is strongly associated with the brand on different social networking websites. For example,

ngvyenxo: "(Pic. 4) My first and last time wearing these culottes. Popped the stitching right after this photo was taken. $-\square \square$ \% Culottes: @bcbgeneration // Bodysuit and heels: @forever21 \#fashiondiaries \#ootdmagazine \#ootdshare \#fashifeen \#fashionfury \#myff \#ootd \#justperfoutfits \#fashionaddictx0 \#fashionfly \#fashionlivesonootd \#ootdfash \#queenoutfits \#declareyourstyle \#F21xMe \#bcbgeneration \#upsideofflorida" [16];

Miss Jones: "I love@Forever21... It is my new favorite place to shop for ANY occasion! \#DeclareYourStyle" [17].
Users can demonstrate their brand loyalty not only by posting pictures with outfits and leaving positive comments, but also by just posting messages with the hashtag. Thus, it can be assumed that hashtags in corporate social networking are used in compliance with We-strategy. Generally, hashtags are used by companies to trace their followers, receive feedback from them, and to expand their audience.

Some brands launch hashtagging campaigns that are seen as an implementation of You-strategy. For example, Lay's asked their followers to share their experience and comment on their favourite chip taste, using hashtag \#DoUsAFlavour. This campaign was aimed at receiving feedback, the company showed their interest in customers' opinion with the marketing purpose. Lay's initiated discussion by adhering to You-strategy:

R: "Midday snack fun with the team. @LaysCanada \#DoUsAFlavor \#DoUsAFlavour \#yumm \#chips \#snack" [17];

Southern Biscuits \& Gravy: "How cute is my Mom?! She got the last few bags of Southern Biscuits and Gravy at the Wal-Mart in Lawrenceburg, TN (near where my family is from)! She was telling everyone who would listen! -) I love you Mom!! \#Lays \#DoUsAFlavor \#VoteBiscuits \#Nonnie" [15];

mkinstlinger: "Hey@lays our taste test is underway. \#dousaflavor" [16].

On the one hand, this brand asks its followers to do a favour and help them find new flavour solutions. In this way Lay's initiated communication by indirect address to their followers. But on the other hand, the launch of this campaign should also be considered as an implementation of We-strategy, as social networking users become involved in marketing process and help company expand its business. Respectively, this communicative move helps to build the sense of community.

Some hashtags added to the message are aimed at implementation of I-strategy. Communicants make use of the strategy to attract attention to their posts. For example, \#10YearChallenge has been launched as a social networking campaign that is based on a simple premise - users need to upload photos of themselves 10 years ago compared with their photos these days to see the difference. By adding hashtag \#10YearChallenge to the messages, users demonstrate their wish to attract attention to their personal profiles on social networking services, to be in trend, and to show that they are in trend. The search engine on Instagram reveals more than 4 million posts containing this hashtag. As it has been mentioned, posts containing a hashtag are organized as a hypertext within a particular social networking service. Therefore, users might either click a hashtag, or type it in a search field to get access to all posts dealing with the issue. The other popular hashtags on social networking hashtags representing I-strategy are \#Me (387 million entries on Instagram), \#My (84 million entries on Instagram), \#MyLove (57 million entries on Instagram), \#Journey (16 million entries on Instagram).

As a conclusion it should be stated that hashtags have become an indivisible part of communication via social networking with the main function to structure and arrange posted information according to thematic rubrics within one social networking service. Hashtagging facili- 
tates both information search and the flow of communication. Communicants intentionally add hashtags to their messages to attract attention to their posts, to stay in trend, to attract more users to their personal profile, or to create the sense of community. To fulfill these intentions users employ hashtags within I-, You-, or We-strategy.

\section{REFERENCES}

1. Borisova, I.N. Discursive strategies in spoken dialogue // The Russian informal speech as a feature of urban culture / Ed. by T.V. Matveeva. - Yekaterinburg: Ural federal university, 1996. - P. 21-48.

2. Facebook: number of monthly active users worldwide 20082018 // Number of monthly active Facebook users worldwide as of 4th quarter 2018 (in millions) // The statistics portal [Web https://www.statista.com/statistics/264810/number-ofmonthly-active-facebook-users-worldwide/

3. Faerch, C., \& Kasper, G. (1983a). Strategies in Interlanguage Communication. - London: Longman, 1983. - 248 p.

4. How social media is changing language [Web resource]: http://blog.oxforddictionaries.com/2014/06/social-mediachanging-language/

5. Issers, O.S. Communication strategies and tactics in the Russian speech. $-5^{\text {th }}$ edition. - Moscow.: URSS, 2008. -284 p.

6. Kalt, C. Internet Relay Chat: Channel Management. - 2000 [Web resource]: https://tools.ietf.org/html//rfc2811

7. Number of monthly active Instagram users 2013-2018 // Number of monthly active Instagram users from January 2013 to June 2018 (in millions) // The statistics portal [Web resource]: https://www.statista.com/statistics/253577/numberof-monthly-active-instagram-users/

8. Oxford Dictionaries [Web resource]: https://en.oxforddictionaries.com/definition/hashtag

9. Parker, A. Twitter's Secret Handshake // The New York Times. - $\quad 10.06 .2011$ [Web resource] https://www.nytimes.com/2011/06/12/fashion/hashtags-a- new-way-for-tweets-culturalstudies.html?_r=1\&pagewanted=all

10. Poulisse, N. On the use of compensatory strategies in second language performance / Nanda Poulisse, Theo Bongaerts and Eric Kellerman // Interlanguage Studies Bulletin. - 1984. Vol. 8, No. 1. - P. 70-105.

11. Skovorodnikov, A. P. On the necessity of differentiating notions "rhetoric device", "stylistic figure", "rpeech tactics", and "speech genre" in terminological lexicography // Rhetorics $\leftrightarrow$ Linguistics: Collected papers. - Smolensk, 2004. - Issue 5. - P. 5-12.

12. Tarone, E. Conscious Communication Strategies in interlanguage. In H.D.Brown et al. (Eds.) On TESOL 1977. Washington: TESOL, 1977. - P. 194-203.

13. Twitter: number of monthly active U.S. users 2010-2018 // Number of monthly active Twitter users in the United States from 1st quarter 2010 to 3rd quarter 2018 (in millions) // The statistics portal [Web resource]: https://www.statista.com/statistics/274564/monthly-activetwitter-users-in-the-united-states/

14. U, B. Communicative strategies and tactics and language means of their implementation in Russian informal interpersonal debate: based on blogs: Thesis for Scholarly Degree in Philology: 10.02.01. - the Russian language. - Moscow., 2008. $-232 \mathrm{p}$.

15. Facebook [Web resource]: http://www.facebook.com/

16. Instagram [Web resource]: http://www.instagram.com/

17. Twitter [Web resource]: http://www.twitter.com/

\section{ЛИТЕРАТУРА}

1. Борисова И.Н. Дискурсивные стратегии в разговорном диалоге // Русская разговорная речь как явление городской культуры / Под ред. Т.В. Матвеевой. - Екатеринбург: Урал. гос. ун-т, 1996. - С. 21-48.

2. Иссерс О.С. Коммуникативные стратегии и тактики русской речи. - 5-е изд. - M.: URSS : ЛКИ, 2008. — 284 с.

3. Сковородников А.П. О необходимости разграничения понятий «риторический приём», «стилистическая

фигура», «речевая тактика» и «речевой жанр» в практике терминологической лексикографии // Риторика ↔ Лингвистика: Сб. статей. - Смоленск, 2004. - Вып. 5. - С. 512.

4. У Б. Коммуникативные стратегии и тактики и языковые средства их реализации в русскоязычной неформальной межличностной дискуссии: на материале Интернетдневников: диссертация ... кандидата филологических наук: 10.02.01 - русский язык. - М., 2008. - 232 с. 